Article

\title{
New Aspects on the Modeling of Dithiolactone-Mediated Radical Polymerization of Vinyl Monomers
}

\author{
Anete Joceline Benitez-Carreón ${ }^{1}$, Jesús Guillermo Soriano-Moro ${ }^{2}$, Eduardo Vivaldo-Lima ${ }^{1,3, * \mathbb{D} \text {, }}$ \\ Ramiro Guerrero-Santos ${ }^{4}\left(\mathbb{D}\right.$ and Alexander Penlidis ${ }^{3}$ (D) \\ 1 Departamento de Ingeniería Química, Facultad de Química, Universidad Nacional Autónoma de México, \\ Ciudad de Mexico 04510, Mexico; anjobeca_23@hotmail.com \\ 2 Centro de Química, Instituto de Ciencias, Benemérita Universidad Autónoma de Puebla (BUAP), Edif. IC8, \\ Ciudad Universitaria, Puebla 72570, Mexico; jesus.soriano@correo.buap.mx \\ 3 Institute for Polymer Research (IPR), Department of Chemical Engineering, University of Waterloo, \\ Waterloo, ON N2L 3G1, Canada; penlidis@uwaterloo.ca \\ 4 Centro de Investigación en Química Aplicada (CIQA), Blvd. Enrique Reyna 140, Saltillo, Coahuila 25140, \\ Mexico; ramiro.guerrero@ciqa.edu.mx \\ * Correspondence: vivaldo@unam.mx; Tel.: +52-55-5622-5226
}

Received: 14 October 2019; Accepted: 7 November 2019; Published: 10 November 2019

\begin{abstract}
A kinetic model for the dithiolactone-mediated radical polymerization of vinyl monomers based on the persistent radical effect and reversible addition (negligible fragmentation) was used to calculate the polymerization rate and describe molar mass development in the polymerization of methyl methacrylate at $60{ }^{\circ} \mathrm{C}$, using 2,2-azobisisobutyronitrile (AIBN) as an initiator, as well as dihydro-5-phenyl-2(3H)-thiophenethione (DTL1) and dihydro-2(3H)-thiophenethione (DTL2) as controllers. The model was implemented in the PREDICI commercial software. A good agreement between experimental data and model predictions was obtained.
\end{abstract}

Keywords: dithiolactones; RAFT polymerization; kinetic modeling; vinyl monomers; methyl methacrylate

\section{Introduction}

Reversible deactivation radical polymerization (RDRP) techniques have become important in the last three decades [1]. They provide versatile routes to synthesize polymers with tailored architectures [2]. The most studied methodologies which have emerged are nitroxide-mediated polymerization (NMP), atom transfer radical polymerization (ATRP), and reversible addition-fragmentation chain-transfer (RAFT) polymerization [3]. However, other RDRP techniques such as iodine-transfer polymerization (ITP) [4], telluride-mediated polymerization (TERP) [5], and organostibine-mediated polymerization [5] have also been proposed.

RAFT polymerization is considered one of the most successful RDRP techniques. In RAFT polymerization, propagating free radical molecule 1 adds to RAFT agent $\mathbf{2}$ (see Figures 1 and 2), thus producing intermediate radical 3 (one-arm adduct), which undergoes $\beta$-scision, yielding back the reactants or producing dormant polymer (macro RAFT agent) 4 and radical R [6]. The main equilibrium reactions consist of the formation of intermediate radical 6 (two-arm product) and its fragmentation into free radical 1 and dormant polymer 4 (see Figure 3). In the "intermediate radical termination" (IRT) model [7], an additional reaction is considered, namely the cross-termination between free radical 1 and the intermediate radical 6, thus producing a star-shaped polymer (three-arm dead polymer), as seen in Figure 4 [6]. It is worth mentioning that further investigation has led to the 
assumption of side reactions between the three-arm adduct $\mathbf{7}$ with a propagating radical 1 to yield intermediate radical $\mathbf{6}$ and a dead polymer [8]. Variations of the IRT model have also been considered: reversible IRT [9] and the occurrence of cross-termination of the intermediate radical with oligomeric radicals only (the IRTO model) [10]. A reversible reaction between intermediate radical 6 and the original RAFT agent 2, producing a secondary intermediate radical that may undergo further RAFT process, has also been proposed [11].

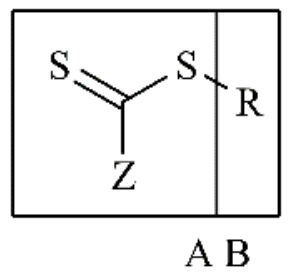

Figure 1. General chemical structure of a reversible addition-fragmentation chain-transfer (RAFT) agent (denoted as $\mathrm{AB}$ in the modeling equations below).

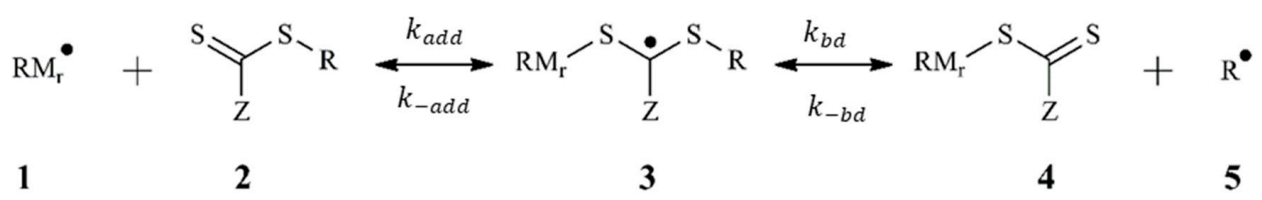

Figure 2. Reversible chain transfer to the RAFT agent (pre-equilibrium).

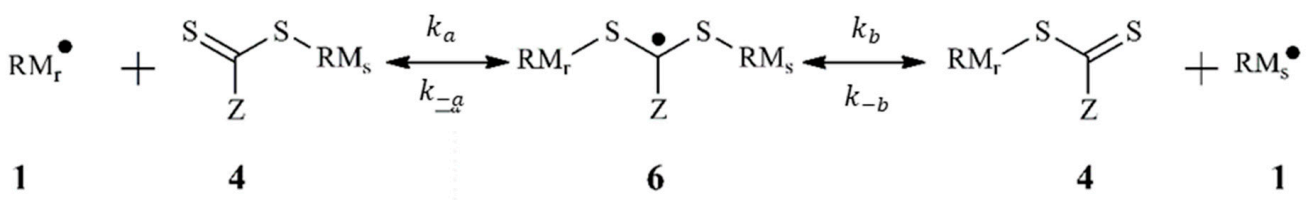

Figure 3. Chain equilibration (addition-fragmentation).

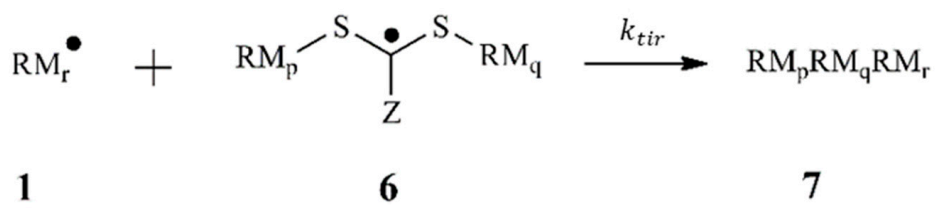

Figure 4. Intermediate radical termination (IRT).

Dithiolactones are the cyclic counterpart to dithioester and thiocarbonylthio compounds, which are used as RAFT agents. However, as seen in Figure 5, there is no fragmentation in dithiolactone-mediated free-radical polymerizations (DTLMP), and the addition reaction is reversible [12,13].

In a previous publication from our group, we modeled the DTLMP of styrene using $2,2^{\prime}$-azobisisobutyronitrile (AIBN) as the initiator and $\gamma$-phenyl- $\gamma$-butyrodithiolactone as the controller [14].

In this contribution, we address the DTLMP of methyl methacrylate (MMA) using dihydro-5-phenyl-2(3H)-thiophenethione-whose common name is $\gamma$-phenyl- $\gamma$-butyrodithiolactone (referred to as DTL1 in the remainder of our contribution) — and dihydro-2(3H)-thiophenethione-whose common name is $\gamma$-butyrodithiolactone (referred to as DTL2 in the remainder of our contribution)-as controllers, from both experimental and mathematical modeling perspectives. 

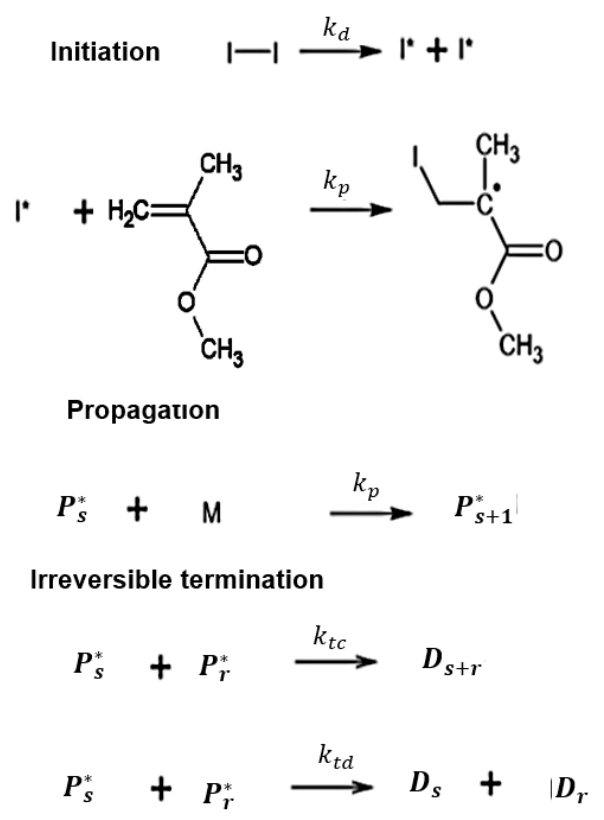

Reversible addition<smiles>[X]C(=C)CC1CCC(=S)S1</smiles>

Reversible cross-termination



Figure 5. Polymerization scheme for dithiolactone-mediated (DTLM) radical polymerization of vinyl monomers.

\section{Experimental}

As mentioned above, the system studied in this contribution was the polymerization of MMA using AIBN as initiator and DTL1 as well as DTL2 as controllers. The polymerizations were carried out at $333.15 \mathrm{~K}\left(60^{\circ} \mathrm{C}\right)$ using two molar ratios of DTL1 and DTL2 (monomer:controller:initiator ratios of 300:2:1 and 300:4:1) [13,15].

\subsection{Polymerization Procedure}

A stock solution of AIBN in MMA was prepared first, then split into several heavy-wall glass tubes, and mixed with calculated amounts of controller (DTL1 or DTL2). Mixtures were degassed by three freeze-thaw-pump cycles, sealed, and heated at $333.15 \mathrm{~K}$ in a thermostated oil bath. A reference experiment was carried out using the original stock solution without the chain transfer agent. Polymers were isolated by precipitation in methanol. Monomer conversion was gravimetrically determined by duplicate, in all cases [13].

\subsection{Measurement of Molar Mass Characteristics}

Molar mass distributions were determined by size exclusion chromatography (SEC) or gel permeation chromatography (GPC) with a Hewlett Packard (HP) modular system comprising an auto injector, a Polymer Laboratories $5.0 \mu \mathrm{m}$ bead-size guard column, and by three linear PLgel columns (106, 105 and $103 \AA$ ), with differential refractive index detector (HP 147 A) and ultraviolet (UV) detector. The eluent was tetrahydrofuran (THF) at a flow rate of $1 \mathrm{~cm}^{3} \mathrm{~min}^{-1}$ at $313.15 \mathrm{~K}$. The system was calibrated using narrow poly(methyl methacrylate) standards (ranging from 620 to $1.52 \times 10^{6} \mathrm{~g} \mathrm{~mol}^{-1}$ ). Data acquisition was performed using Polymer Laboratories GPC software. All measurements were obtained by duplicate [13].

\section{Modeling}

\subsection{Polymerization Scheme}

The polymerization scheme used for our simulations was based on the reaction mechanism proposed by Soriano-Moro et al. for DTL1 [13,15], shown in Figure 5. This polymerization scheme corresponded to a RAFT polymerization without fragmentation. Its implementation in the PREDICI 
software package of CiT [16,17], which was the numerical tool to carry out the simulations, is shown in Table 1. The initiation, propagation and bimolecular radical termination correspond to conventional free radical polymerization [14,18,19]. The first reversible addition [20], second reversible addition (which is the reaction between two molecules of intermediate radicals generating a new type of adduct (see Figure 6)) [13], and reversible cross-termination are reactions due to the presence of dithiolactone controller molecules, as explained above [13-15]. Also shown in Table 1 are parameter sources [14,18-23]. It can be observed in Table 1 that our values of $K=k_{\text {add }} / k_{\text {-add }}$ for DTL1 and DTL2, which were in the range of $10^{5}-10^{6} \mathrm{~m}^{3} \mathrm{kmol}^{-1}$ for conventional RAFT agents, were slightly low.

Table 1. Polymerization scheme and kinetic rate constants used.

\begin{tabular}{|c|c|c|c|c|}
\hline Reaction & Step Pattern & $\begin{array}{l}k\left(\mathrm{~m}^{3} \mathrm{kmol}^{-1} \mathrm{~s}^{-1}, \text { Unless }\right. \\
\text { Otherwise Stated) }\end{array}$ & DTL1 [Source] & DTL2 [Source] \\
\hline $\begin{array}{c}\text { Initiator } \\
\text { decomposition }\end{array}$ & $I \rightarrow I^{\bullet}+I^{\bullet}$ & $k_{d}\left(s^{-1}\right)$ & $4 \times 10^{-6}[21]$ & $4 \times 10^{-6}[21]$ \\
\hline First propagation & $I^{\bullet}+M \rightarrow P_{s=1}^{\bullet}$ & $k_{i}$ & 833 [18] & 833 [18] \\
\hline Propagation & $P_{s}^{\bullet}+M \rightarrow P_{s+1}^{\bullet}$ & $k_{p}$ & $685.9[22,23]$ & $685.9[22,23]$ \\
\hline \multirow{2}{*}{$\begin{array}{c}\text { First reversible } \\
\text { addition }\end{array}$} & $P_{s}^{\bullet}+D T L \rightarrow P_{s} D T L^{\bullet}$ & $k_{\text {add }}$ & $2.3 \times 10^{3}$ [this work] & $8.1 \times 10^{3}$ [this work] \\
\hline & $P_{S} D T L^{\bullet} \rightarrow P_{s}^{\bullet}+D T L$ & $k_{-a d d}$ & $2.622 \times 10^{-2}$ [this work] & $8.6 \times 10^{-2}$ [this work] \\
\hline \multirow{2}{*}{$\begin{array}{c}\text { Reversible } \\
\text { cross-termination }\end{array}$} & $P_{s}^{\bullet}+P_{r} D T L \bullet \rightarrow P_{s} D T L P_{r}$ & $k_{r t}$ & $5 \times 10^{2}[14]$ & $5 \times 10^{3}$ [this work] \\
\hline & $P_{s} D T L P_{r} \rightarrow P_{s}^{\bullet}+P_{r} D T L \bullet$ & $k_{-r t}$ & $2 \times 10^{-4}$ [this work] & $2 \times 10^{-4}$ [this work] \\
\hline \multirow{2}{*}{$\begin{array}{l}\text { Irreversible } \\
\text { termination }\end{array}$} & $P_{s}^{\bullet}+P_{r}^{\bullet} \rightarrow D_{s}+D_{r}$ & $k_{t d}$ & $3.40 \times 10^{7}[22,23]$ & $3.40 \times 10^{7}[22,23]$ \\
\hline & $P_{s}^{\bullet}+P_{r}^{\bullet} \rightarrow D_{s+r}$ & $k_{t c}$ & $9.78 \times 10^{7}[22,23]$ & $9.78 \times 10^{7}[22,23]$ \\
\hline \multirow{2}{*}{$\begin{array}{l}\text { Second reversible } \\
\text { addition }\end{array}$} & $P_{s} D T L \bullet+P_{r} D T L \bullet \rightarrow P_{s} D T L D T L P_{r}$ & $k_{e s}$ & $2 \times 10^{2}$ [this work] & $2 \times 10^{2}$ [this work] \\
\hline & $P_{s} D T L D T L P_{r} \rightarrow P_{s} D T L^{\bullet}+P_{r} D T L^{\bullet}$ & $k_{-e s}$ & $4 \times 10^{-4}$ [this work] & $4 \times 10^{-4}$ [this work] \\
\hline
\end{tabular}
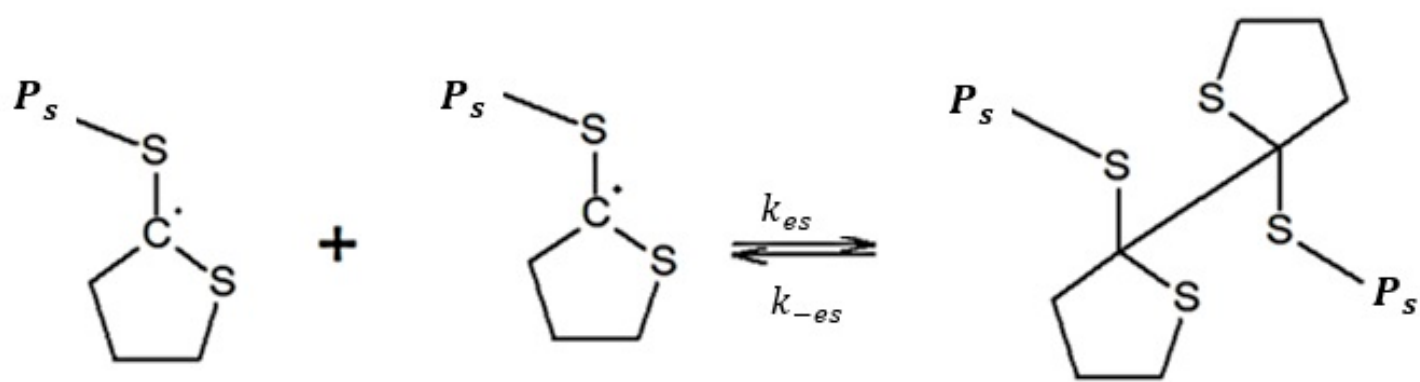

Figure 6. Second reversible addition reaction.

\subsection{Diffusion-Controlled (DC) Effects}

Free-volume theory was used to account for diffusion-controlled (DC) effects in (conversion-dependent) kinetic rate constants. The expressions used for DC-effects are summarized in Table $2[14,18] . \beta_{i}$ in the expressions of Table 2 are the free-volume "overlap" parameters for the $i$-th reaction, with $i$ accounting for termination, propagation, forward and reverse addition (first and second), and reversible cross-termination; $T$ and $T g_{i}$ are the reaction temperature and glass transition temperature of component $i$, respectively; $\alpha_{i}$ is volumetric expansion coefficient for species $i ; V_{i}$ and $V_{t}$ denote the volumes of species $i$ and total volumes, respectively; $v_{f 0}$ and $v_{f}$ denote fractional free volume at initial conditions and at calculation time, respectively. The free-volume parameters are summarized in Table 3. As mentioned earlier, the simulations were carried out using the PREDICI software of CiT, version 11.3.0. 
Table 2. Mathematical expressions for diffusion-controlled (DC)-effects.

\begin{tabular}{|c|c|c|}
\hline Reaction & Mathematical Expression & $\begin{array}{c}\beta \text { Parameters for DC-Expressions } \\
\text { [Source] }\end{array}$ \\
\hline Propagation & $k_{p}=k_{p}^{0} \operatorname{Exp}\left[-\beta_{p}\left(\frac{1}{V_{f}}-\frac{1}{V_{f 0}}\right)\right]$ & $0.01[14]$ \\
\hline \multirow{2}{*}{ First reversible addition } & $k_{a d d}=k_{a d d}^{0} \operatorname{Exp}\left[-\beta_{a d d}\left(\frac{1}{V_{f}}-\frac{1}{V_{f 0}}\right)\right]$ & $0.01[14]$ \\
\hline & $\begin{array}{c}k_{-a d d}= \\
k_{-a d d}^{0} \operatorname{Exp}\left[-\beta_{-a d d}\left(\frac{1}{V_{f}}-\frac{1}{V_{f 0}}\right)\right]\end{array}$ & $0.01[14]$ \\
\hline \multirow{2}{*}{ Reversible cross-termination } & $k_{r t}=k_{r t}^{0} \operatorname{Exp}\left[-\beta_{r t}\left(\frac{1}{V_{f}}-\frac{1}{V_{f 0}}\right)\right]$ & 0.45 [this work] \\
\hline & $k_{-r t}=k_{-r t}^{0} \operatorname{Exp}\left[-\beta_{-r t}\left(\frac{1}{V_{f}}-\frac{1}{V_{f 0}}\right)\right]$ & 0.45 [this work] \\
\hline \multirow{2}{*}{ Irreversible Termination } & $k_{t c}=k_{t c}^{0} \operatorname{Exp}\left[-\beta_{t c}\left(\frac{1}{V_{f}}-\frac{1}{V_{f 0}}\right)\right]$ & $0.45[14]$ \\
\hline & $k_{t d}=k_{t d}^{0} \operatorname{Exp}\left[-\beta_{t d}\left(\frac{1}{V_{f}}-\frac{1}{V_{f 0}}\right)\right]$ & $0.45[14]$ \\
\hline \multirow{2}{*}{ Second reversible addition } & $k_{e s}=k_{e s}^{0} \operatorname{Exp}\left[-\beta_{e s}\left(\frac{1}{V_{f}}-\frac{1}{V_{f 0}}\right)\right]$ & 0.55 [this work] \\
\hline & $k_{-e s}=k_{-e s}^{0} \operatorname{Exp}\left[-\beta_{-e s}\left(\frac{1}{V_{f}}-\frac{1}{V_{f 0}}\right)\right]$ & 0.55 [this work] \\
\hline Fractional Free Volume & $V_{f}=\sum_{i=1}^{N}[0 . c$ & $\left.\left(T-T_{g i}\right)\right] \frac{V_{i}}{V_{t}}$ \\
\hline
\end{tabular}

Table 3. Other free-volume parameters.

\begin{tabular}{ccc}
\hline Parameter & Value & Reference \\
\hline$\alpha_{\text {MMA }}\left(\mathrm{K}^{-1}\right), T g_{M M A}(\mathrm{~K})$ & $0.001,143$ & {$[24],[25]$} \\
\hline$\alpha_{\text {PMMA }}\left(\mathrm{K}^{-1}\right), T g_{P M M A}(\mathrm{~K})$ & $0.0048,392$ & {$[24],[25]$} \\
\hline$\alpha_{\text {DTL1 }}\left(\mathrm{K}^{-1}, T g_{D T L 1}(\mathrm{~K})\right.$ & $0.0001,173.15$ & {$[14],[14]$} \\
\hline$\alpha_{\text {DTL2 }}\left(\mathrm{K}^{-1}\right), T g_{D T L 2}(\mathrm{~K})$ & $0.0001,173.15$ & This work, this work \\
\hline
\end{tabular}

\subsection{Parameter Estimation Strategy}

Literature values were used for $k_{d}, k_{i}, k_{p}, k_{t c}$ and $k_{t d}$ (see Table 1). Given the wide variation range on reported $k_{t c}$ and $k_{t d}$ values for MMA and the large effect of the ratio $k_{t c} / k_{t d}$ on the evolution of $\mathrm{M}_{\mathrm{n}}$ versus conversion profiles, a careful evaluation (mimicking a sensitivity analysis) of the reported values was carried out. The best results were obtained with the parameters reported in the Watpoly software database [22]. Once these parameters were fixed, a more detailed parameter sensitivity analysis was conducted with the remaining parameters, the ones related to the RDRP behavior of dithiolactones $\left(k_{a d d}, k_{-a d d}, k_{r t}, k_{-r t}, k_{e s}\right.$, and $\left.k_{-e s}\right)$. The parameters accounting for DC-effects were assumed to be similar to the ones estimated for the polymerization of styrene using DTL1 [14] and the same for both controllers (DTL1 and DTL2). They are summarized in Table 2 (last column).

The overall strategy used in our study is similar to the one used by Gomez-Reguera et al. [26].

\section{Results and Discussion}

\subsection{Polymerization of MMA Using DTL1}

The effect of DTL1 concentration on polymerization rate, expressed as conversion versus time, number average molar mass $\left(\mathrm{M}_{\mathrm{n}}\right)$, and molar mass dispersity $(Đ)$, is shown in Figure 7. As expected, it can be observed in Figure 7 that increasing DTL1 concentration resulted in a slower polymerization rate, a lower molar mass, and a slightly lower Đ. 


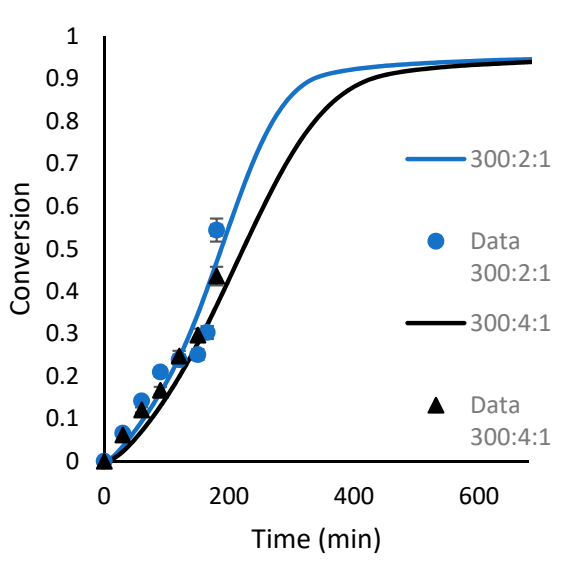

(a)

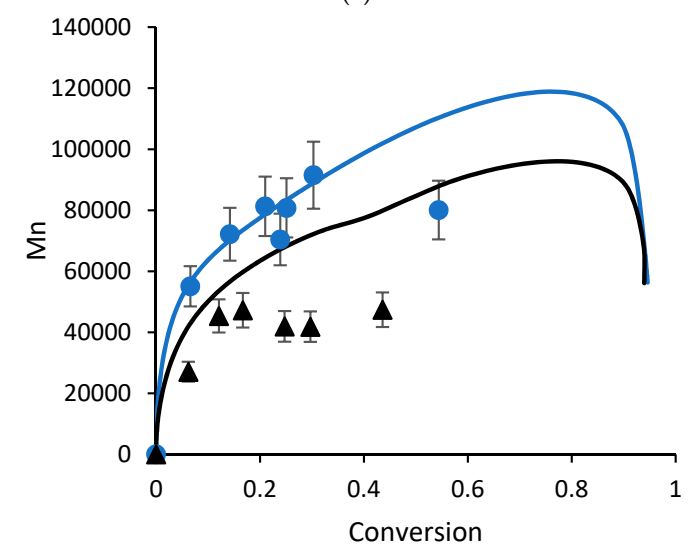

(b)

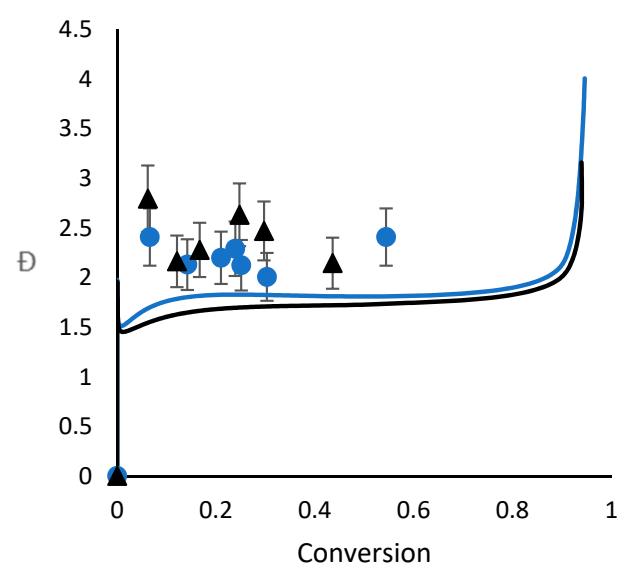

(c)

Figure 7. Comparison of model predictions and experimental data of (a) monomer conversion versus time, (b) number average molar mass versus conversion, and (c) Đ versus conversion. [methyl methacrylate (MMA)]:[ $\gamma$-phenyl- $\gamma$-butyrodithiolactone (DTL1)]:[2,2-azobisisobutyronitrile $($ AIBN)]=300:2:1 for EXP 1 and 300:4:1 for EXP 2.

Overall, a fair agreement can be observed in Figure 7 between the calculated and experimental profiles, with some deviations. The evolution of polymerization rate and molecular weight development were captured well by the model in the case of 300:2:1, but significant deviations were observed for both profiles in the case of 300:4:1. Several attempts to improve the agreement between calculated and experimental profiles of $M_{n}$ versus conversion for the case of 300:4:1 by fine-tuning some of the kinetic rate constants or DC effect parameters were made. If the agreement was improved, the changes 
resulted in the worsening of the agreement for the conversion versus time profiles, as well as the obtainment of a very poor performance for the case of 300:2:1. This is not uncommon in modelling attempts when multi-response data points are used with the same set of parameters. Therefore, the behavior of $M_{n}$ after 20\% monomer conversion observed in the case of 300:4:1 suggests either a high(er) experimental error occurring in this case, or, more likely, the presence of side reactions not considered in the polymerization scheme when the controller content was high. The deviations are also evident in Figure 7 for the case of $Đ$ versus conversion. Again, this points towards the direction of side reactions affecting the data-reactions which are unaccounted for in the polymerization mechanism and, hence, in the subsequent mathematical model. It is also possible that the parameters associated to DC effects may have become conversion dependent [26]. A similar overall performance was observed in the case of polymerization of styrene using DTL1 $[13,14]$.

A comparison of calculated and experimental full molar mass distributions (MMDs) for the cases using DTL1 is shown in Figure 8. The calculated MMDs of Figure 8 are narrower than the experimental ones. This result agrees with the $Đ$ versus conversion profiles of Figure 7, where calculated $Đ$ values are lower than the experimental ones. However, the time evolution of the MMDs and the effect of controller on both $\mathrm{M}_{\mathrm{n}}$ and the spread of the MMD were well captured by the model. As stated earlier, the disagreement between calculated and experimental profiles of $Đ$ versus conversion and time evolution of the MMDs may be attributed to chain transfer side reactions [21]. Several possible alternatives and changes in the polymerization scheme, including reversible fragmentation (full RAFT case) and other side reactions, were indeed simulated in this study, but no significant improvement was obtained.
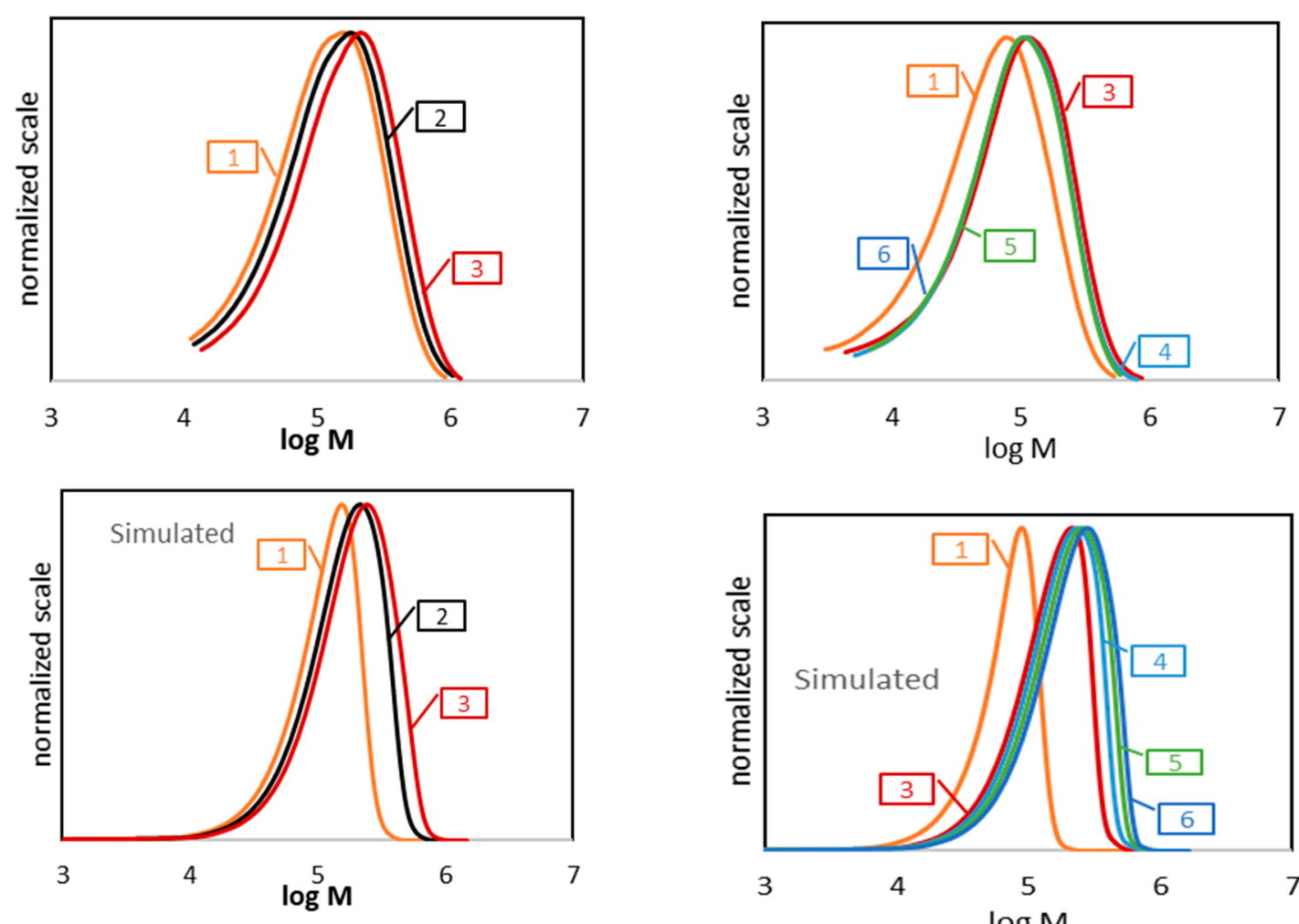

(a)

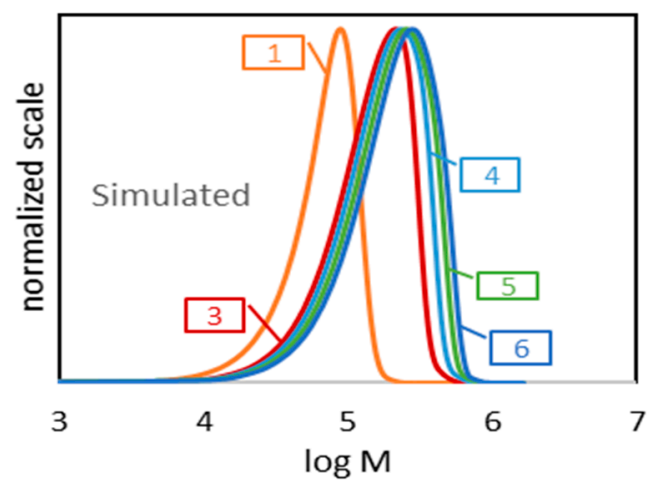

(b)

Figure 8. Evolution of molar-mass distributions for polymerizations using DTL1 (experimental and simulated): (a) 300:2:1 and (b) 300:4:1. Labels: "1" = 30, "2" = 60, "3" = 90, "4" = 120, " 5 " = 150, "6" = $180 \mathrm{~min}$. 
In our previous investigation on the polymerization of styrene using DTL1 or benzyl dithiopropianate (BDP), overall radical concentrations were measured using electro-spin resonance (ESR) spectroscopy. Overall radical concentrations in the order of $10^{-7}-10^{-6} \mathrm{kmol} \mathrm{m}^{-3}$ were obtained $[13,15]$. Though the model used included the calculation of concentrations of all the species involved in the polymerization scheme, no comparison between calculated and experimental profiles of overall radical concentration versus time was presented. Moad et al. [27] pointed out that the reversible addition mechanism for the DTLMP of vinyl monomers proposed herein (see Figure 5) seems unlikely since, for control, most of the propagating species would need to be present at the dormant state (polymer product in the forward direction of the reversible addition reaction of Figure 5, or species $\mathrm{P}_{\mathrm{S}} \mathrm{DTL}{ }^{-}$in Table 1). They added that ESR experiments (triangles in Figure 9) showed that a high concentration of radicals was not present during polymerization, thus implying that the mechanism would suggest that the final product should also have the $\mathrm{P}_{\mathrm{s}} \mathrm{DTL} \cdot$ structure. In order to gain more insight regarding this issue, we carried out simulations of overall radical concentration versus time for both styrene and MMA DTLMPs, using DTL1 for styrene and MMA, as well as DTL2 for MMA. The results using DTL1 are shown in Figures 9 and 10. (Results using DTL2 are shown in Section 4.2).

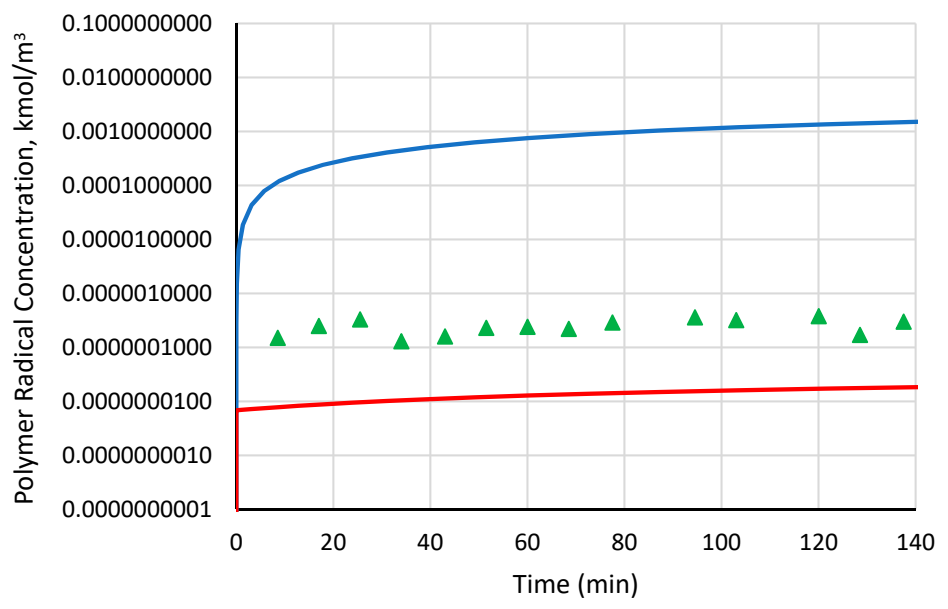

Figure 9. Comparison of experimental $[13,15]$ and calculated profiles of polymer radical concentration versus time for the dithiolactone-mediated free-radical polymerizations (DTLMP) of styrene using DTL1: overall polymer radical (blue solid line); polymer radicals excluding $\mathrm{P}_{\mathrm{S}} \mathrm{DTL} \bullet$ (red solid line); experimental data (green triangles). Monomer:controller:initiator: 300:2:1.

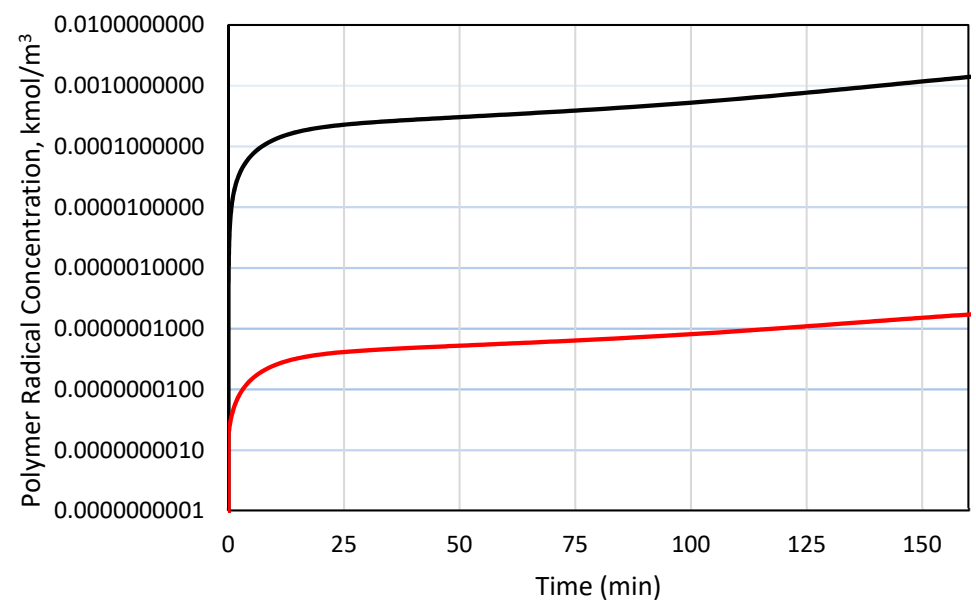

Figure 10. Calculated profiles of polymer radical concentration in the free radical polymerization of MMA using DTL1: overall polymer radicals (black solid line) and polymer radicals excluding dormant polymer $\mathrm{P}_{\mathrm{s}} \mathrm{DTL} \bullet$ (red solid line). 
It can be observed in Figure 9 that the predicted overall concentration of polymer radicals (blue solid line, which includes "dormant" polymer $\mathrm{P}_{\mathrm{s}} \mathrm{DTL} \mathrm{*}^{\bullet}$ ) exceeded by almost four orders of magnitude the experimental profile. It can also be observed in that figure that the calculated concentration of polymer radicals excluding $\mathrm{P}_{\mathrm{S}} \mathrm{DTL}{ }^{\bullet}$ was one order of magnitude lower than the experimental profile of the overall polymer radical concentration. This result indicates that the level of control experimentally obtained would require a much higher content of dormant polymer $\mathrm{P}_{\mathrm{s}} \mathrm{DTL} \mathrm{L}^{\bullet}$, as pointed out by Moad et al. [27]; this suggests that our proposed polymerization scheme may be incomplete, pointing again towards other side reactions in the mechanism, as postulated above during the discussion of the experimental results of Figures 7 and 8.

As mentioned earlier, no measurements of polymer radical concentration versus time were obtained for the case of the DTLM polymerization of MMA. However, calculated profiles were generated, and the ranges are like those of Figure 9. Figure 10 shows calculated profiles of overall polymer radical concentration (black solid line) and polymer radicals excluding the "dormant" population $\left(\mathrm{P}_{\mathrm{S}} \mathrm{DTL}{ }^{\bullet}\right.$, red solid line). It can again be observed that most of the polymer radical population is made out of dormant polymer $\mathrm{P}_{\mathrm{s}} \mathrm{DTL}^{\bullet}$, which allows the polymerization to be controlled.

\subsection{Polymerization of MMA Using DTL2}

The effect of controller concentration on the polymerization rate and molar mass development for the polymerization of MMA using DTL2 was also addressed. It can be observed in Figure 11 (upper plot) that the agreement between the calculated and experimental profiles of conversion versus time is very good for the case of 300:2:1, but large deviations were observed for the case of 300:4:1. It is worth noting that the experimental profile corresponding to a higher RAFT content (grey triangles) resulted in higher conversions than the case of 300:2:1, which was contrary to the expected performance. The calculated profiles, however, showed the correct trend with polymerization rate decreasing as RAFT content increased. This result suggests that our experimental profile of conversion versus time for the case of 300:4:1 may have been in error. The agreement between the experimental and calculated profiles of $\mathrm{M}_{\mathrm{n}}$ versus conversion, on the other hand, is very good for both RAFT concentration levels (see middle plot of Figure 11). It is interesting to notice that the predicted profile of $Đ$ versus conversion for the case of 300:4:1 also agrees very well with the experimental one, as observed in the bottom plot of Figure 11. The agreement between the calculated and experimental profiles of $Đ$ versus conversion for the case of 300:2:1, on the other hand, is again poor, as with DTL1.

The polymerization of MMA using AIBN and DTL1 or DTL2 controllers showed hybrid behavior between RDRP and conventional chain transfer radical polymerization. This hybrid behavior has also been observed in the RAFT polymerization of MMA using cumyl phenyldithioacetate [20]. This hybrid behavior strongly depends on temperature; at temperatures below $45^{\circ} \mathrm{C}$, the conventional character dominates, whereas controlled behavior dominates at higher temperatures [20].

The comparison of calculated and experimental MMDs shown in Figure 12 confirms the information provided by the middle and bottom plots of Figure 11. It can be observed that the calculated MMDs for the case of 300:2:1 were narrower than the experimental ones. In the case of system 300:4:1, the agreement between the calculated and experimental MMDs is very good, except for the experimental MMD at very low conversions, which was much broader, verifying a dominant conventional chain transfer behavior in that case, as alluded to above. 


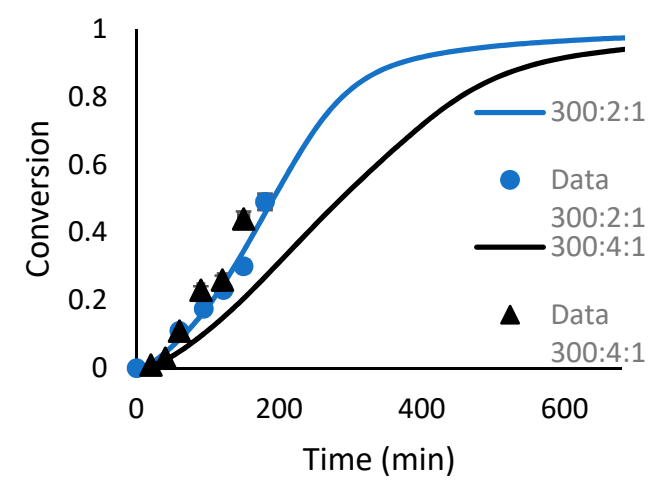

(a)

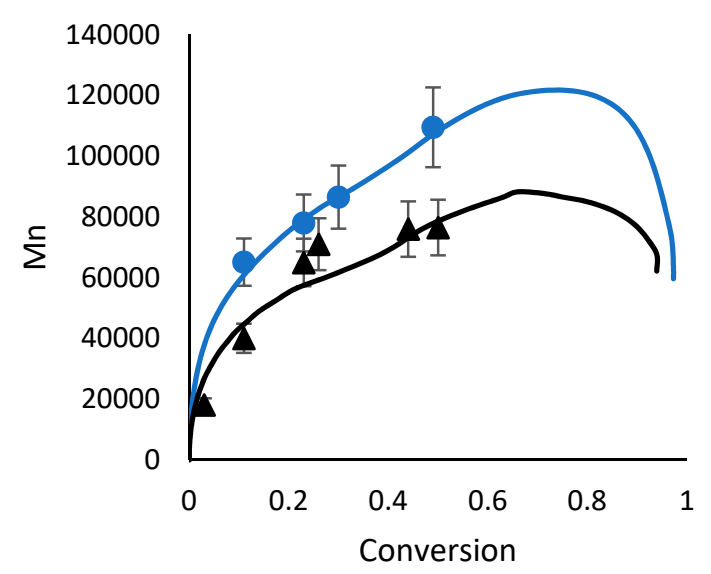

(b)

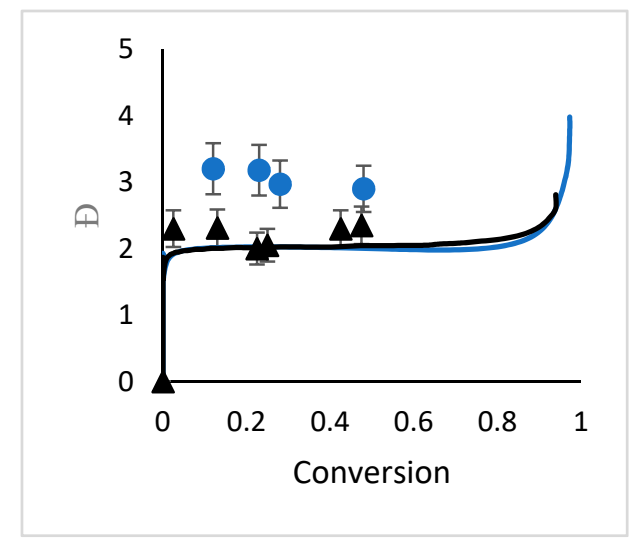

(c)

Figure 11. Comparison of model predictions and experimental data for (a) monomer conversion versus time, (b) number average molar mass versus conversion, and (c) Đ versus conversion. [MMA]:[dihydro-2(3)-thiophenethione (DTL2)]:[AIBN] = 300:2:1 for EXP 1 and 300:4:1 for EXP 2.

Finally, the calculated profiles of overall polymer radical concentration and concentration of dormant polymer $\left(\mathrm{P}_{\mathrm{s}} \mathrm{DTL}^{\bullet}\right)$ versus time for the case of DTLM polymerization of MMA using DTL2 are shown in Figure 13. As in the case using DTL1 earlier, it can be observed that large amounts of dormant polymer were required to obtain adequate control. 

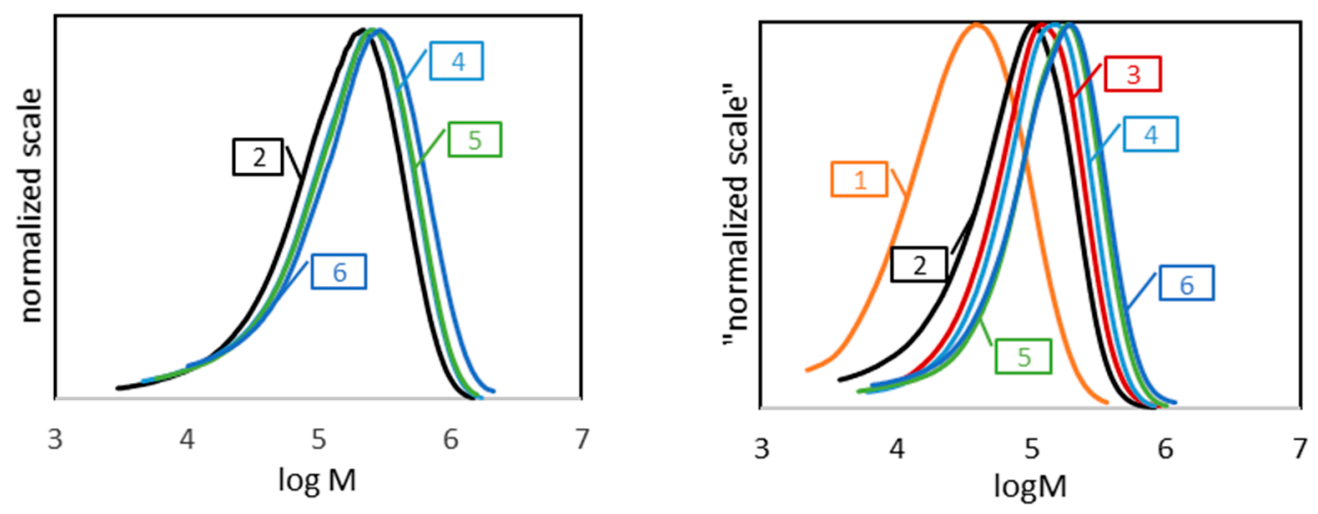

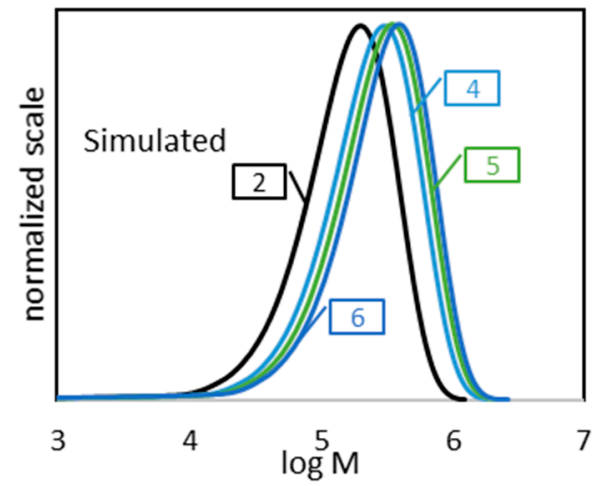

(a)

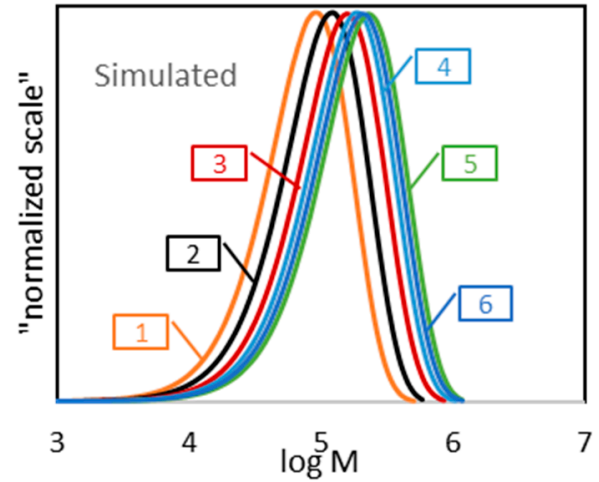

(b)

Figure 12. Evolution of the molar-mass distributions with DTL2 (experimental shown at the top and simulated at the bottom): (a) 300:2:1 and (b) 300:4:1. Labels: " 1 " $=40, " 2$ " $=60$, “3" = 90, " 4 " = 120, “ 5 " $=150$, " 6 " $=180 \mathrm{~min}$.

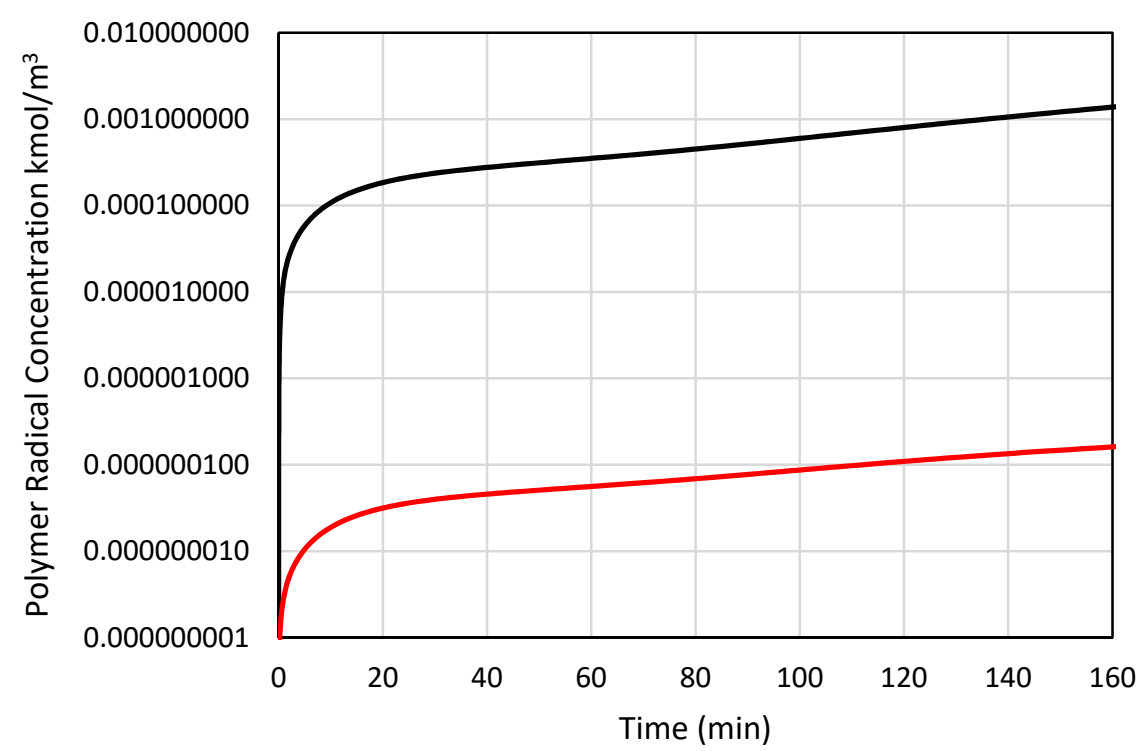

Figure 13. Calculated profiles of polymer radical concentration in the free radical polymerization of MMA using DTL2: overall polymer radicals (black solid line) and polymer radicals excluding dormant polymer $\mathrm{P}_{\mathrm{S}} \mathrm{DTL} \bullet$ (red solid line). 


\subsection{Some Thoughts on Future Research Steps}

Masoumi et al. [6] used a sequential Bayesian Monte Carlo model discrimination (SBMCMD) method to discriminate between two rival RAFT models, the so-called slow-fragmentation (SF) method [28] and one type of IRT model [29]). They found that if one of the two competing models represents the 'real' mechanism behind the RAFT process, the SBMCMD framework can identify the correct model by analyzing the data from the most informative experiments designed by the model discrimination steps. However, for the system studied in that paper, if the 'real' model was not known beforehand, the method was not able to discriminate between the SF and IRT models, based on polymerization rate and molar mass development data (conversion versus time and molar mass averages versus conversion experimental profiles). The bottom-line conclusion is that additional independent experimental information (e.g., concentrations of intermediate products) is needed to get more conclusive results.

As stated in Section 4.1, we carried out additional simulations under different mechanistic variations, including trials using the full RAFT model (the inclusion of fragmentation), but no significantly better results were obtained. More comprehensive results in that direction will be presented by our group in future contributions.

\section{Conclusions}

The free radical polymerization of MMA in the presence of AIBN and DTL1 or DTL2 at $333.15 \mathrm{~K}$ was studied experimentally and modeled using a polymerization scheme where only reversible addition was considered (fragmentation neglected). The agreement between the experimental and modeling profiles of conversion versus time, average molar mass and full MMDs can range from fair to very-good. Our results complement our previous study on the polymerization of styrene using AIBN and DTL1.

Though the polymerization scheme based on reversible addition only seems to be adequate to describe the overall performance of dithiolactone-mediated free radical polymerizations, described typically by polymerization rate and average molar mass development, the fact that the global description of the system, considering a wide range of experimental conditions and independent responses was difficult to obtain by using a single set of model parameters, suggests that the proposed polymerization scheme may be incomplete.

Our modeling results suggest that high concentrations of a dormant polymer $\left(\mathrm{P}_{\mathrm{S}} \mathrm{DTL} \mathrm{L}^{\bullet}\right)$ are required to provide adequate control of the polymerization. This result further suggests that the polymerization scheme may be incomplete. This is an issue that requires further experimental and mechanistic considerations in the area of DTLMP.

Author Contributions: A.J.B.-C. performed all the simulations and parameter estimation procedure, guided by E.V.-L. and A.P., R.G.-S. and J.G.S.-M. conceived the experimental research. J.G.S.-M. conducted all experiments and characterization. E.V.-L. and R.G.-S. provided technical direction to the project. A.J.B.-C. wrote the paper with feedback from J.G.S.-M., while E.V.-L. and A.P. revised the different intermediate versions until the final document.

Funding: This research was funded by: (a) Consejo Nacional de Ciencia y Tecnología (CONACYT, México), MEng scholarship granted to A.J.B.-C.; (b) DGAPA-UNAM, Projects PAPIIT IG100718, IV100119, and PASPA sabbatical support to E.V.-L. at the University of Waterloo, in Ontario, Canada; (c) Facultad de Química-UNAM, research funds granted to E.V.-L. (PAIP 5000-9078); (d) VIEP-BUAP, research funds granted to J.G.S.-M. and (e) Natural Sciences and Engineering Research Council (NSERC) of Canada.

Conflicts of Interest: The authors declare no conflict of interest.

\section{References}

1. Jenkins, A.D.; Jones, R.G.; Moad, G. Terminology for reversible-deactivation radical polymerization previously called "controlled" radical or "living" radical polymerization (IUPAC Recommendations 2010). Pure Appl. Chem. 2009, 82, 483-491. [CrossRef]

2. Luo, Y.D.; Chiu, W.Y. Synthesis and kinetic analysis of DPE controlled radical polymerization of MMA. J. Polym. Sci. Polym. Chem. 2009, 47, 6789-6800. [CrossRef] 
3. Vivaldo-Lima, E.; Jaramillo-Soto, G.; Penlidis, A. Nitroxide-Mediated Polymerization (NMP). In Encyclopedia of Polymer Science and Technology, 4th ed.; Mark, H.F., Ed.; John Wiley \& Sons: New York, NY, USA, 2016; pp. $1-48$.

4. Kim, K.; Kim, Y.; Ko, N.R.; Choe, S. Effect of molecular weight on the surface morphology of crosslinked polymer particles in the RITP-dispersion polymerization. Polymer 2011, 52, 5439-5444. [CrossRef]

5. Yamago, S. Development of organotellurium-mediated and organostibine-mediated living radical polymerization reactions. J. Polym. Sci. Part A Polym. Chem. 2016, 44, 1-12. [CrossRef]

6. Masoumi, S.; Duever, T.A.; Penlidis, A.; Azimi, R.; López-Domínguez, P.; Vivaldo-Lima, E. Model discrimination between RAFT polymerization models using sequential Bayesian methodology. Macromol. Theory Simul. 2018, 27, 1800016. [CrossRef]

7. Monteiro, M.J.; de Brouwer, H. Intermediate Radical Termination as the Mechanism for Retardation in Reversible Addition-Fragmentation Chain Transfer Polymerization. Macromolecules 2001, 34, 349-352. [CrossRef]

8. Buback, M.; Vana, P. Mechanism of Dithiobenzoate-Mediated RAFT polymerization: A missing reaction Step. Macromol. Rapid Commun. 2006, 27, 1299. [CrossRef]

9. Barner-Kowollik, C.; Buback, M.; Charleux, B.; Coote, M.L.; Drache, M.; Fukuda, T.; Goto, A.; Klumperman, B.; Lowe, A.B.; Mcleary, J.B.; et al. Mechanism and Kinetics of Dithiobenzoate-Mediated RAFT Polymerization. I. The Current Situation. J. Polym. Sci. Part A Polym. Chem. 2006, 44, 5809-5831. [CrossRef]

10. Konkolewicz, D.; Hawkett, B.S.; Gray-Weale, A.; Perrier, S. RAFT Polymerization Kinetics: Combination of Apparently Conflicting Models. Macromolecules 2008, 41, 6400-6412. [CrossRef]

11. Li, C.; He, J.; Liu, Y.; Zhou, Y.; Yang, Y. Probing the RAFT Process Using a Model Reaction between Alkoxyamine and Dithioester. Aust. J. Chem. 2012, 65, 1077-1089. [CrossRef]

12. Inuit, T.; Yamanishi, K.; Sato, E.; Matsumoto, A. Organotellurium-Mediated Living Radical Polymerization (TERP) of Acrylates Using Ditelluride Compounds and Binary Azo Initiators for the Synthesis of High-Performance Adhesive Block Copolymers for On-Demand Dismantlable Adhesion. Macromolecules 2013, 46, 8111-8120. [CrossRef]

13. Soriano-Moro, J.G.; Rico-Valverde, J.C.; Enriquez-Mendrano, F.J.; Maldonado-Textle, H.; Vivaldo-Lima, E.; Acosta-Ortiz, R.; Guerrero-Santos, R. Toward a Living Radical Polymerization of Styrene by Using Dithiolactone as a New Type of Mediating Agent. Macromol. Rapid Commun. 2008, 29, 80-85. [CrossRef]

14. Soriano-Moro, J.G.; Jaramillo-Soto, G.; Guerrero-Santos, R.; Vivaldo-Lima, E. Kinetics and Molecular Weight Development of Dithiolactone-Mediated Radical Polymerization of Styrene. Macromol. React. Eng. 2009, 3, 178-184. [CrossRef]

15. Soriano-Moro, J.G. Síntesis y Caracterización de Ditiolactonas y su Empleo Como Agentes de Transferencia en la Polimerización RAFT. Ph.D. Thesis, Programa de Doctorado en Tecnología de Polímeros, CIQA, Saltillo, México, February 2008.

16. Wulkow, M. Computer Aided Modeling of Polymer Reaction Engineering-The Status of Predici, 1-Simulation. Macromol. React. Eng. 2008, 2, 461-494. [CrossRef]

17. Hungenberg, K.D.; Wulkow, M. Modeling and Simulation in Polymer Reaction Engineering: A Modular Approach; Wiley-VCH: Weinheim, Germany, 2018; pp. 92, 256.

18. Beurmann, S.; Buback, M. Rate coefficients of free-radical polymerization deduced from pulsed laser experiments. Prog. Polym. Sci. 2002, 27, 191-254. [CrossRef]

19. Pallares, J.; Jaramillo-Soto, G.; Flores-Cataño, C.; Vivaldo Lima, E.; Lona, L.M.F.; Penlidis, A. A Comparison of Reaction Mechanisms for Reversible Addition-Fragmentation Chain Transfer Polymerization Using Modeling Tools. J. Macromol. Sci. A Pure Appl. Chem. 2006, 43, 1293. [CrossRef]

20. Barner-Kowollik, C.; Quinn, J.F.; Nguyen, T.L.U.; Heuts, J.P.A.; Davis, T.P. Kinetic investigations of reversible addition fragmentation chain transfer polymerizations: Cumyl phenyldithioacetate mediated homopolymerizations of styrene and methyl methacrylate. Macromolecules 2001, 34, 7849-7857. [CrossRef]

21. Jaramillo-Soto, G.; Castellanos-Cardenas, M.L.; García-Moran, P.; Vivaldo-Lima, E.; Luna-Barcenas, G.; Pendilis, A. Simulation of Reversible Addition-Fragmentation Chain Transfer (RAFT) Dispersion Polymerization in Supercritical Carbon Dioxide. Macromol. Theory Simul. 2008, 17, 280-289. [CrossRef]

22. Jung, W. Mathematical Modeling of Free-Radical Six-Component Bulk and Solution Polymerization. Master's Thesis, Department of Chemical Engineering, University of Waterloo, Waterloo, ON, Canada, 2008. 
23. Gao, J.; Penlidis, A. A Comprehensive Simulator Database Package for Reviewing Free-Radical Copolymerizations. J. Macromol. Sci. Part C Polym. Rev. 1998, 38, 651-780. [CrossRef]

24. Vivaldo-Lima, E.; García-Pérez, R.; Celedón-Briones, O.J. Modeling of the Free-Radical Copolymerization Kinetics with Crosslinking of Methyl Methacrylate/Ethylene Glycol Dimethacrylate Up to High Conversions and Considering Thermal Effects. Evista Sociedad Química México 2003, 47, 22-33.

25. Faldi, A.; Tirrell, M.; Lodge, T.P.; von Meerwall, E. Monomer Diffusion and the Kinetics of Methyl Methacrylate Radical Polymerization at Intermediate to High Conversion. Macromolecules 1994, 27, 4184-4192. [CrossRef]

26. Gómez-Reguera, J.A.; Vivaldo-Lima, E.; Gabriel, V.A.; Dubé, M.A. Modeling of the Free Radical Copolymerization Kinetics of n-Butyl Acrylate, Methyl Methacrylate and 2-ethylhexyl Acrylate Using PREDICI. Processes 2019, 7, 395. [CrossRef]

27. Moad, G.; Rizzardo, E.; Thang, S.H. Living Radical Polymerization by the RAFT Process-A Second Update. Aust. J. Chem. 2009, 62, 1402-1472. [CrossRef]

28. Barner-Kowollik, C.; Quinn, J.F.; Morsley, D.R.; Davis, T.P. Modeling the reversible addition-fragmentation chain transfer process in cumyl dithiobenzoate-mediated styrene homopolymerizations: Assessing rate coefficients for the addition-fragmentation equilibrium. J. Polym. Sci. Part A Polym. Chem. 2001, 39, 1353-1365. [CrossRef]

29. Wang, A.R.; Zhu, S. Modeling the reversible addition-fragmentation transfer polymerization process. J. Polym. Sci. Part A Polym. Chem. 2003, 41, 1553-1566. [CrossRef]

(C) 2019 by the authors. Licensee MDPI, Basel, Switzerland. This article is an open access article distributed under the terms and conditions of the Creative Commons Attribution (CC BY) license (http://creativecommons.org/licenses/by/4.0/). 